\section{Public Health} Genomics
Public Health Genomics 2018;21:228-237

DOI: $10.1159 / 000501464$
Received: February 7, 2019 Accepted: June 11, 2019 Published online: July 19, 2019

\title{
Public Understanding and Opinions regarding Genetic Research on Alzheimer's Disease
}

\author{
Saida Kent ${ }^{a}$ Shoshana H. Bardach ${ }^{b, c}$ Xuan Zhang ${ }^{d}$ Erin L. Abner ${ }^{b, c}$ \\ Joshua D. Grille Gregory A. Jicha ${ }^{a, b}$ \\ a University of Kentucky College of Medicine, Lexington, KY, USA; b Sanders-Brown Center on Aging, University of \\ Kentucky, Lexington, KY, USA; ' University of Kentucky College of Public Health, Lexington, KY, USA; ${ }^{d}$ Johns Hopkins

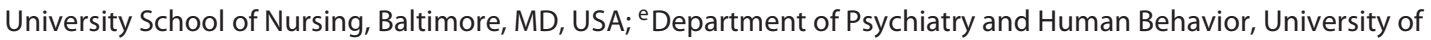 \\ California, Irvine, Irvine, CA, USA
}

\section{Keywords}

Alzheimer's disease $\cdot$ Genetic research $\cdot$ Research participation · Concerns · Knowledge · Survey . Questionnaire

\section{Abstract \\ Background: Participants willing to provide genetic sam- ples are needed to propel research on Alzheimer's disease (AD) treatment and prevention forward. A limited public un- derstanding of what $A D$ genetic research entails and con- cerns about participation may constitute recruitment chal- lenges. Objectives: This study seeks to understand how well older adults understand AD genetic research and whether their understanding is related to concerns about participa- tion or willingness to engage. Methods: Our surveys includ- ed a mock consent form with corresponding knowledge and opinion questions regarding $A D$. The surveys were mailed to participants from the University of Kentucky Alzheimer's Dis- ease Center and to a list of randomly selected individuals within the same age range from a local voter registration list. Descriptive and multivariable linear regression analyses were conducted. Results: The returned surveys $(n=502)$}

\section{KARGER}

() 2019 S. Karger AG, Basel

E-Mail karger@karger.com

www.karger.com/phg demonstrated limits to what the respondents understood immediately after reading the relevant material, with a mean summary knowledge score of 74.5 out of 100 . While comprehension gaps were not related to level of concern or willingness to engage, concerns were related to willingness to engage. Concerns were greater among individuals not actively involved in research, individuals from minority groups, and those with higher levels of education. Conclusions: Focusing on concerns specifically, rather than on knowledge more generally, may help increase participation.

(c) 2019 S. Karger AG, Basel

\section{Introduction}

Initial genetic discoveries in Alzheimer's disease (AD) began with recognition of mutations in the amyloid precursor protein, presenilin 1, and presenilin 2 as causes of autosomal dominant $\mathrm{AD}$, followed by the identification of the $\varepsilon 4$ allele of the apolipoprotein $\mathrm{E}$ gene as a risk factor for sporadic AD. Since that time, over 20 genetic risk loci for sporadic $\mathrm{AD}$ have been identified [1], providing insights into molecular pathways that may be altered in

\footnotetext{
Shoshana H. Bardach

Sanders-Brown Center on Aging, University of Kentucky

1030 S. Broadway, Suite 5

Lexington, KY 40504 (USA)

E-Mail shbardach@uky.edu
} 
$\mathrm{AD}$ and identifying targets for prevention and treatment. These discoveries are only possible through the involvement of large numbers of research volunteers [2].

Certain risk genes for sporadic AD can be identified through blood tests, buccal swabs, and spit kits (e.g., APOE), though this testing is typically not recommended in standard clinical care, since at present these results do not provide clear clinical implications [3]. However, in the research context, genetic testing is pervasive [4] and can help identify individuals at greater risk for developing memory impairments [5]. Unfortunately, genetic testing can also introduce the potential for genetic discrimination, with potential implications for both participants and their family members [6]. AD genetic research participation decisions should be based on understanding the risks and benefits [7].

Many individuals value knowing about their personal disease risk and are frequently willing to undergo and pay for $\mathrm{AD}$ predictive genetic tests $[8,9]$. In the research context, however, personal disease risk information often is not shared with participants $[10,11]$. Additionally, certain groups are underrepresented in $\mathrm{AD}$ genetic research, e.g., minorities and individuals with lower levels of education [8]. The same groups have a history of research mistreatment and lack of adequate consent [7], which may lead to reluctance to participate due to concerns about privacy or use of genetic information. Concerns may be exacerbated in situations where there is uncertainty regarding what $\mathrm{AD}$ genetic research entails.

Prior research suggested a reasonable understanding of $\mathrm{AD}$ genetic risk results, but demonstrated that older adults may have more comprehension difficulties than younger adults [12]. Older adults may be more likely to see the value in biobank participation - one type of genetic research - than younger adults, but they may be equally or even less likely than younger adults to report willingness to participate [13-15]. Given that older adults are typically the target population for genetic research on $\mathrm{AD}$ prevention and treatment, there is a need for assessment of the comprehension of and attitudes toward such research among older adults [16].

This study sought to understand how well older adults understand $\mathrm{AD}$ genetic research when presented with descriptive information mirroring the content of a research consent form, and whether certain factors were related to understanding. To enhance generalizability, both current (University of Kentucky Alzheimer's Disease Center [UKADC] participants) and potential (voter registration list [VRL]) older research participants were surveyed. This paper also explores how understanding is related to concerns about participation and willingness to engage. We hypothesized that older adults would have gaps in their understanding of $\mathrm{AD}$ genetic research, and that these gaps would be related to concerns about genetic research and willingness to engage.

\section{Subjects and Methods}

\section{Study Design}

A paper survey was distributed by mail, including a study description and a postage-paid return envelope. The UKADC participants had previously expressed their preference for mail communication rather than email communication; email addresses were also largely unavailable for the UKADC participants and were completely unavailable for the VRL participants. Accordingly, we used postal mail to distribute the survey to both groups. The cover letter included all elements of informed consent; no formal documentation of consent was required. The surveys were mailed and returned between June 2016 and August 2016.

\section{Participants}

Two groups were surveyed. First, volunteers $(n=594)$ enrolled in the UKADC longitudinal cohort with Clinical Dementia Rating global scores of 0 or 0.5 , representing no or questionable memory and thinking problems, were surveyed $[17,18]$. In addition, the UKADC manages a list from 2010 of registered voters in Fayette County Kentucky who indicated a willingness to be contacted for aging-related research, not $\mathrm{AD}$ research specifically. After the UKADC list had been generated, summary statistics on age, sex, race, and educational attainment were computed. Using those results, the VRL was randomly sampled $(n=608)$ within the age range of the UKADC participants to get the groups as similar as possible (Table 1).

\section{Instrument}

The survey began with the Quality of Informed Consent (QUIC), a valid and reliable measure of participants' understanding of clinical trials, modified to focus on AD genetic research [19]. The survey had 7 sections, each beginning with a short paragraph from a standard genetic research consent form followed by a series of questions (paragraphs available by request to the corresponding author). Each paragraph included answers to the knowledge comprehension questions that immediately followed. The 7 sections were: (1) purpose of genetic research (5 questions); (2) risks of genetic research (6 questions); (3) genetic data storage and access (8 questions); (4) result information sharing (6 questions); (5) the right to withdraw and ability to destroy samples (3 questions); (6) future research participation based on genetic results (6 questions); and (7) types of genetic research (5 questions).

Each question used a 5-point Likert scale (strongly agree to strongly disagree) (Tables 2-4). The questions assessed comprehension of the material just presented, concerns about privacy or use of genetic material, and willingness to get involved in research. Both the cover letter and the first page of the survey specifically indicated that the focus was on $\mathrm{AD}$ genetic research. Throughout the survey, the context for all questions was genetic research in the area of AD. While not all individual questions explicitly mentioned $\mathrm{AD}$, the survey repeatedly referenced this focal area. For 
Table 1. Demographic characteristics and unadjusted mean summary scores

\begin{tabular}{|c|c|c|c|c|}
\hline Age, years & $78.8 \pm 6.6$ & $78.5 \pm 7.2$ & $79.3 \pm 5.3$ & 0.21 \\
\hline \multicolumn{5}{|l|}{ Sex } \\
\hline Male & $212(42.2)$ & $132(40.1)$ & $80(46.2)$ & \multirow[t]{2}{*}{0.19} \\
\hline Female & $290(57.8)$ & $197(59.9)$ & $93(53.8)$ & \\
\hline College & $340(68.3)$ & $236(72.4)$ & $104(60.5)$ & 0.02 \\
\hline \multicolumn{5}{|l|}{ Race } \\
\hline Non-White & $45(9.0)$ & $29(8.8)$ & $16(9.3)$ & \multirow[t]{2}{*}{0.88} \\
\hline White & $456(91.0)$ & $299(91.2)$ & $157(90.7)$ & \\
\hline \multicolumn{5}{|l|}{ Marital status } \\
\hline No & $206(41.4)$ & $135(41.2)$ & $71(41.8)$ & 0.90 \\
\hline Summary willingness score & $89.81 \pm 15.14$ & $90.50 \pm 14.31$ & $88.49 \pm 16.57$ & 0.16 \\
\hline
\end{tabular}

Values are presented as mean \pm SD or $n(\%)$. All summary scores have a maximum value of 100, with higher scores indicating higher knowledge, higher concerns, and higher willingness. VRL, voter registration list; QUIC, Quality of Informed Consent.

instance, the first section, which focused on the purpose of genetic research, provided the following paragraph prior to the questions:

\section{SECTION 1: What is the purpose of genetic research?}

The purpose of the study is to collect and store blood samples and health information to learn about the role genes play in health and disease, specifically about the development of Alzheimer's disease. Results of these genetic studies may reveal information about you and your family members' risk for Alzheimer's disease.

As can be seen in this excerpt, while some of the language refers to genetic research more broadly, the accompanying text orients respondents to the focus on AD.

Basic demographic information (age, sex, race, education, and marital status) was collected. A preliminary validation of the survey was conducted with several individuals in the research clinic to make sure that the items were understood and that responses were appropriate to the questions asked.

To ensure readability and applicability, the content was matched to current consent form templates from the University of Kentucky Institutional Review Board (IRB) website and existing consents for AD clinical trials. While no formal psychometric testing of the survey was conducted, a team of interdisciplinary investigators, including neurologists, neuropsychologists, social workers, and gerontologists, reviewed the survey iteratively to ensure its face validity and readability.

Analysis

Summary scores of the modified QUIC were calculated for knowledge comprehension, concerns about privacy and use of ge- netic material, and willingness to engage, according to established procedures [19]. We separated privacy and genetic concerns to tease out the nature of the concerns. The privacy items focused explicitly on privacy concerns, whereas those about genetic concerns focused on issues related to preferences for sharing and use of genetic materials; we interpreted expressions of a preference for restricted use of genetic information as genetic concerns.

Correct answers, endorsement of concern, and positive attitude answers were assigned a score of 100. Incorrect answers, lack of concern, and negative attitude answers were assigned a score of 0 . "Not sure" was assigned a score of 50 , because it is preferred that participants recognize areas of uncertainty rather than be certain of false beliefs. To mirror the established QUIC analysis procedures, responses of "strongly agree" and "agree" were given the same score, as were responses of "strongly disagree" and "disagree." Unanswered questions were not scored. Summary scores were then calculated by adding the scores for each item and dividing them by the number of nonmissing items (Tables 2-4). The resulting summary scores ranged from 0 to 100 . The items for knowledge, concerns, and privacy were all predetermined in the questionnaire design phase, and the scoring procedures followed the QUIC guidelines, with higher scores representing greater comprehension, more positive attitudes, and greater endorsement of concerns. All survey questions are included in one of the tables, with each table representing responses that measure one of the measured constructs: knowledge comprehension (Table 2), concerns about privacy and use of genetic material (Table 3), and willingness to engage (Table 4).

Descriptive statistics were used to compare the UKADC and VRL groups. To assess a potential nonresponse bias, respondents were compared to nonrespondents within each group in regard to 
Table 2. Alzheimer's genetic Quality of Informed Consent (QUIC) comprehension items in ascending order of comprehension

\begin{tabular}{|c|c|c|c|c|c|c|c|}
\hline Question & $\begin{array}{l}\text { Strongly } \\
\text { agree }\end{array}$ & Agree & Not sure & Disagree & $\begin{array}{l}\text { Strongly } \\
\text { disagree }\end{array}$ & Missing & $\begin{array}{l}\text { Mean QUIC item } \\
\text { score (SD) }\end{array}$ \\
\hline Genetic studies will inform me about my risk for Alzheimer's disease & $100(19.9)$ & $159(31.7)$ & $187(37.3)$ & $41(8.2)$ & $10(2.0)$ & $5(1.0)$ & $29.07(33.52)$ \\
\hline $\begin{array}{l}\text { I will be contacted if during the research testing, my genes show any disease risk } \\
\text { factors }\end{array}$ & $58(11.6)$ & $205(40.8)$ & $80(15.9)$ & $108(21.5)$ & $34(6.8)$ & $17(3.4)$ & $37.53(44.00)$ \\
\hline The main goal of genetic research is to help me directly & $59(11.8)$ & $99(19.7)$ & $122(24.3)$ & $164(32.7)$ & $48(9.6)$ & $10(2.0)$ & $55.49(43.06)$ \\
\hline $\begin{array}{l}\text { If I withdraw from the study, all of my genetic information and samples containing } \\
\text { my genetic information will be destroyed }\end{array}$ & $32(6.4)$ & $101(20.1)$ & $84(16.7)$ & $171(34.1)$ & $102(20.3)$ & $12(2.4)$ & $64.29(43.26)$ \\
\hline No one will ever be able to find out who I am, based on my genetic information & $39(7.8)$ & $82(16.3)$ & $101(20.1)$ & $184(36.7)$ & $80(15.9)$ & $16(3.2)$ & $64.71(42.04)$ \\
\hline There is always a way to get my results from research studies if I want them & $18(3.6)$ & $57(11.4)$ & $185(36.9)$ & $153(30.5)$ & $68(13.5)$ & $21(4.2)$ & $65.18(36.21)$ \\
\hline $\begin{array}{l}\text { If my sample is identified there is a federal law (GINA) that protects me from } \\
\text { discrimination }\end{array}$ & $79(15.7)$ & $223(44.4)$ & $108(21.5)$ & $56(11.2)$ & $22(4.4)$ & $14(2.8)$ & $72.95(37.21)$ \\
\hline Others not directly connected to the study will have access to my genetic information & $62(12.4)$ & $246(49.0)$ & $100(19.9)$ & $56(11.2)$ & $25(5.0)$ & $13(2.6)$ & $73.21(38.12)$ \\
\hline There is a possibility that my genetic sample could be identified & $51(10.2)$ & $265(52.8)$ & $103(20.5)$ & $45(9.0)$ & $25(5.0)$ & $13(2.6)$ & $75.15(36.65)$ \\
\hline $\begin{array}{l}\text { The researchers taking my DNA sample will be the only ones to use my genetic } \\
\text { information }\end{array}$ & $26(5.2)$ & $41(8.2)$ & $107(21.3)$ & $201(40.0)$ & $113(22.5)$ & $14(2.8)$ & $75.31(36.25)$ \\
\hline I can decide to not be told any results of my genetic testing & $57(11.4)$ & $256(51.0)$ & $100(19.9)$ & $43(8.6)$ & $15(3.0)$ & $31(6.2)$ & $77.07(35.20)$ \\
\hline The GINA law may not completely protect my privacy and confidentiality & $79(15.7)$ & $254(50.6)$ & $118(23.5)$ & $21(4.2)$ & $18(3.6)$ & $12(2.4)$ & $80.00(31.62)$ \\
\hline $\begin{array}{l}\text { Research that examines all of my genetic information involves the greatest risk that } \\
\text { the information could be linked back to me or my family }\end{array}$ & $85(16.9)$ & $221(44.0)$ & $88(17.5)$ & $24(4.8)$ & $1(0.2)$ & $83(16.5)$ & $83.53(29.20)$ \\
\hline $\begin{array}{l}\text { I will be contacted if during the research testing, the results show I have a high risk } \\
\text { factor for a disease that currently has available treatment }\end{array}$ & $113(22.5)$ & $279(55.6)$ & $60(12.0)$ & $23(4.6)$ & $9(1.8)$ & $18(3.6)$ & $87.19(28.44)$ \\
\hline $\begin{array}{l}\text { If I withdraw from the study, some of my genetic information already shared will } \\
\text { continue to be used }\end{array}$ & $142(28.3)$ & $298(59.4)$ & $38(7.6)$ & $12(2.4)$ & $1(0.2)$ & $11(2.2)$ & $93.48(20.41)$ \\
\hline $\begin{array}{l}\text { Genetic research may entail varying levels of genetic } \\
\text { information being collected depending on the study }\end{array}$ & $118(23.5)$ & $324(64.5)$ & $36(7.2)$ & $2(0.4)$ & $6(1.2)$ & $16(3.2)$ & $94.65(17.94)$ \\
\hline $\begin{array}{l}\text { Genetic studies will help researchers find genes associated with higher and/or lower } \\
\text { risk for Alzheimer's disease }\end{array}$ & $252(50.2)$ & $211(42.0)$ & $31(6.2)$ & $4(0.8)$ & $1(0.2)$ & $3(0.6)$ & $95.90(15.45)$ \\
\hline My genetic information could be used for multiple research studies & $174(34.7)$ & $285(56.8)$ & $24(4.8)$ & $4(0.8)$ & $4(0.8)$ & $11(2.2)$ & $95.93(16.40)$ \\
\hline The main goal of genetic research is to help others in the future & $330(65.7)$ & $152(30.3)$ & $8(1.6)$ & $5(1.0)$ & $2(0.4)$ & $5(1.0)$ & $97.79(13.29)$ \\
\hline
\end{tabular}

Values denote $n$ (\%) unless specified otherwise. Higher scores reflect greater comprehension. Note that in some Alzheimer's disease genetic studies, the correct answer to these questions could differ based on the study design. The answers identified as correct above were the accurate answers based on the information in the summary paragraphs provided to the participants. Bold type refers to correct responses.

age, sex, education, and race, using the unpaired $t$ test for age and the $\chi^{2}$ test for the remaining variables. Multivariable linear regression was used to assess the associations between summary scores and respondent group, adjusting for education (college and above vs. no college), marital status (married vs. unmarried), race (White vs. non-White), sex (male vs. female), and age. The analyses of willingness also controlled for summary knowledge score. The analyses were performed in SAS $9.4^{\circledR}$, and statistical significance was set at 0.05 .

\section{Results}

\section{Respondents}

Fourteen UKADC surveys and 123 VRL surveys were returned due to a change in address or death of the recipient. A total of 502 surveys were received, including
329 (56.7\%) from UKADC participants and 173 (34.7\%) from VRL participants.

The UKADC respondents had higher education (71.7\% with college education vs. $58.2 \%, p=0.001)$ and were less frequently from a minority racial group (8.8 vs. $17.9 \%, p=0.04$ ) than the UKADC nonrespondents. The VRL respondents were younger (mean age 79.3 vs. 80.7 years, $p=0.007$ ) and less frequently from a minority racial group ( 9.2 vs. $17.0 \%, p=0.048$ ) than the VRL nonrespondents. No other significant differences between respondents and nonrespondents were observed in either group.

The mean age of the overall sample was 78.8 years; $57.8 \%$ were female, and $58.6 \%$ were currently married (Table 1). The participants were highly educated, since $68.3 \%$ had at least a college degree. Most were White. The participants in the research group were significantly more 
Table 3. Alzheimer's genetic Quality of Informed Consent (QUIC) privacy and genetic items survey responses

\begin{tabular}{|c|c|c|c|c|c|c|c|c|}
\hline Question & $\begin{array}{l}\text { Con- } \\
\text { struct }\end{array}$ & $\begin{array}{l}\text { Strongly } \\
\text { agree }\end{array}$ & Agree & Not sure & Disagree & $\begin{array}{l}\text { Strongly } \\
\text { disagree }\end{array}$ & Missing & $\begin{array}{l}\text { Mean item score } \\
\text { (SD) }\end{array}$ \\
\hline I am concerned about the privacy and confidentiality of my genetic information & $\mathrm{P}$ & $29(5.8)$ & $163(32.5)$ & $63(12.5)$ & $167(33.3)$ & $63(12.5)$ & $17(3.4)$ & $46.08(46.52)$ \\
\hline $\begin{array}{l}\text { Concerns about privacy would prevent me from participating in genetic } \\
\text { research }\end{array}$ & $\mathrm{P}$ & $8(1.6)$ & $25(5.0)$ & $91(18.1)$ & $229(45.6)$ & $136(27.1)$ & $13(2.6)$ & $16.05(29.73)$ \\
\hline $\begin{array}{l}\text { I am okay with my genetic information being shared without my direct } \\
\text { involvement }\end{array}$ & G & $89(17.7)$ & $270(53.8)$ & $77(15.3)$ & $31(6.2)$ & $18(3.6)$ & $17(3.4)$ & $18.04(32.92)$ \\
\hline $\begin{array}{l}\text { I would prefer to have my genetic information "open access" to allow maximal } \\
\text { use of my genetic information for Alzheimer's research }\end{array}$ & G & $114(22.7)$ & $217(43.2)$ & $79(15.7)$ & $53(10.6)$ & $24(4.8)$ & $15(3.0)$ & $23.92(37.64)$ \\
\hline $\begin{array}{l}\text { I would prefer to have my genetic information "restricted access" to allow only } \\
\text { NIH approved researchers to use my genetic information for Alzheimer's } \\
\text { research }\end{array}$ & G & $45(9.0)$ & $153(30.5)$ & $67(13.3)$ & $179(35.7)$ & $41(8.2)$ & $17(3.4)$ & $47.73(46.41)$ \\
\hline $\begin{array}{l}\text { I am okay with the researchers sharing my genetic information with "for-profit" } \\
\text { drug companies }\end{array}$ & G & $43(8.6)$ & $177(35.3)$ & $117(23.3)$ & $94(18.7)$ & $59(11.8)$ & $12(2.4)$ & $43.16(43.13)$ \\
\hline $\begin{array}{l}\text { I am okay with researchers making a profit from my genetic information } \\
\text { without receiving any profits myself }\end{array}$ & G & $47(9.4)$ & $219(43.6)$ & $104(20.7)$ & $70(13.9)$ & $47(9.4)$ & $15(3.0)$ & $34.70(41.66)$ \\
\hline $\begin{array}{l}\text { Once I provide genetic samples I would like them to be used indefinitely to } \\
\text { maximize their utility }\end{array}$ & G & $178(35.5)$ & $254(50.6)$ & $47(9.4)$ & $8(1.6)$ & $6(1.2)$ & $9(1.8)$ & $7.61(2.57)$ \\
\hline
\end{tabular}

Values denote $n$ (\%) unless specified otherwise. Bold type signifies responses that indicate concerns with privacy or use of genetic information. P, privacy concerns; G, genetic concerns.

Table 4. Alzheimer's genetic Quality of Informed Consent (QUIC) willingness items survey responses

\begin{tabular}{|c|c|c|c|c|c|c|c|}
\hline Question & $\begin{array}{l}\text { Strongly } \\
\text { agree }\end{array}$ & Agree & Not sure & Disagree & $\begin{array}{l}\text { Strongly } \\
\text { disagree }\end{array}$ & Missing & $\begin{array}{l}\text { Mean item score } \\
\text { (SD) }\end{array}$ \\
\hline It is important to participate in genetic research & $269(53.6)$ & $194(38.6)$ & $27(5.4)$ & $5(1.0)$ & $2(0.4)$ & $5(1.0)$ & $95.88(16.13)$ \\
\hline $\begin{array}{l}\text { I would like to be presented with an opportunity to participate in an experimental } \\
\text { medication trial if I were at high risk for developing Alzheimer's disease }\end{array}$ & $156(31.1)$ & $230(45.8)$ & $78(15.5)$ & $15(3.0)$ & $5(1.0)$ & $18(3.6)$ & $87.81(25.86)$ \\
\hline I would prefer not to be contacted for future research based on my genetic information & $7(1.4)$ & $28(5.6)$ & $61(12.2)$ & $248(49.4)$ & $138(27.5)$ & $20(4.0)$ & $86.41(29.32)$ \\
\hline $\begin{array}{l}\text { Researchers should not knowingly withhold information about promising studies for } \\
\text { which I may be eligible }\end{array}$ & $119(23.7)$ & $278(55.4)$ & $54(10.8)$ & $18(3.6)$ & $11(2.2)$ & $22(4.4)$ & $88.33(27.40)$ \\
\hline $\begin{array}{l}\text { I would be willing to submit my genetic information to a registry to help match me to } \\
\text { Alzheimer's disease research studies based on my genetic information }\end{array}$ & $132(26.3)$ & $279(55.6)$ & $55(11.0)$ & $12(2.4)$ & $3(0.6)$ & $21(4.2)$ & $91.16(22.82)$ \\
\hline
\end{tabular}

Values denote $n$ (\%) unless specified otherwise. Bold type signifies positive attitudes towards/willingness to participate in Alzheimer's disease genetic research.

likely to have a college education or higher $(72.4 \%)$ than those in the VRL group $(60.5 \%, p=0.023)$.

\section{Knowledge of Genetic Research}

Overall, limitations in understanding the complexity of $\mathrm{AD}$ genetic research were identified, with a mean unadjusted summary knowledge score of 74.5 out of 100 . The summary knowledge scores did not differ significantly between the research group and the VRL group (adjusted mean difference -0.7 points, $95 \% \mathrm{CI}-3.0$ to 1.7 , $p=0.57)$.

There were several areas where the responses demonstrated knowledge comprehension gaps (Table 2), including the areas of genetic testing and beliefs about personal benefit. Nearly half of the respondents failed to under- stand that confidentiality could be compromised based on genetic information. More than one-third of the respondents did not understand that their genetic information could be shared, and $43 \%$ did not recognize that their genetic information and samples may not always be destroyed if they withdrew. Regarding comprehension gaps in the area of personal benefit, most respondents failed to understand that there are instances where they cannot get personal genetic results. Nearly one-third of the participants thought that the main goal of genetic research was to help them directly (with an additional quarter of the participants being unsure). Many respondents (52\%) thought that they would be informed about their own risk for $\mathrm{AD}$, and $53 \%$ thought that they would be contacted if their genes showed any disease risk factors. 
Based on the multivariable regression analysis, several sociodemographic factors were associated with knowledge summary scores. The participants with less than a college education had an adjusted mean summary knowledge score of 66.9, compared to 73.0 for those with at least a college education (adjusted mean difference 6.1, 95\% CI $3.6-8.5, p<0.001$ ). The non-White respondents had an adjusted mean summary knowledge score of 66.14 , compared to 73.71 for the White respondents $(p=0.0001)$. In addition, for each additional year of age, the respondents scored 0.30 points lower $(95 \%$ CI -0.5 to $-0.2, p<0.001)$ on the QUIC summary knowledge score $(p=0.0008)$. There were no significant associations between sex or marital status and knowledge scores.

\section{Concerns about Privacy and Use of}

\section{Genetic Information}

The concerns about privacy and use of genetic information were mild (Tables 1,3 ). In the analysis adjusted for respondent group, age, education, race, sex, and marital status, neither privacy concerns nor genetic concerns were related to summary knowledge scores. Based on the regression analysis, there were no significant relationships between any of the demographic variables, including respondent group, and summary privacy concern scores (global $F$ test $p=0.37$ ). For concerns about genetic materials, respondent group, education, and race were all significantly related to genetic concern summary scores. The VRL participants were significantly more concerned about the use of genetic material when compared to the research participants (mean genetic concern score 36.2 vs. $31.2,95 \%$ CI for adjusted mean difference $0.3-9.7, p=$ $0.04)$. The non-White participants were significantly more concerned about the use of genetic material than were the White participants (mean genetic concern score 40.6 vs. $26.7,95 \%$ CI for adjusted mean difference $6.1-$ $21.6, p<0.001)$. Those with a college or higher education had more concerns about genetic information than those with less than a college education (mean genetic concern score 37.08 vs. $30.22,95 \%$ CI for adjusted mean difference $2.0-11.7, p=0.006)$.

\section{Willingness to Participate in Genetic Research}

Overall willingness to participate in genetic research on AD was high, with no single item achieving less than majority agreement (Table 1). Willingness scores and summary knowledge scores were not related when controlling for respondent group, age, education, race, sex, and marital status. Based on the regression analysis, none of the demographic variables examined, including re-

Understanding Genetic Research on AD spondent group, were related to willingness summary scores. Willingness to participate was inversely related both to concerns about genetics (Pearson correlation $-0.212, p<0.001$ ) and to concerns about privacy (Pearson correlation $-0.216, p<0.001$ ).

\section{Discussion}

This study explored the understanding and acceptance of genetic research on $\mathrm{AD}$ among older adults with varying degrees of research engagement. Both current and potential older adult research participants had gaps in their understanding of AD genetic research. While the QUIC does not provide clear guidelines on what is considered a "good" score, a score of 74.5 immediately after viewing the material clearly demonstrates suboptimal knowledge and is slightly lower than the scores found with other instances of the QUIC $[20,21]$. Consistent with prior research exploring knowledge of genetics, the comprehension gaps were greater among those with less education, older individuals, and those of non-White racial groups [22]. These factors should alert researchers to the need for extra time during the consent process to ensure all information is fully understood. Teach-back techniques are often used to confirm comprehension capacity when a researcher is uncertain about a participant's comprehension [23]. Given the complexity of AD genetic research, perhaps this should be done for all participants in key areas where misunderstandings are more common, such as those highlighted in this study. While ensuring fully informed consent might not necessarily increase participation, ensuring a common understanding at the outset may help avoid any potential losses in trust or future research willingness. This might occur if a negative outcome is experienced that was not even recognized as a possibility, or if an anticipated positive result is not realized.

In our study, there were comprehension gaps, but concerns were relatively mild. Comprehension gaps were most notable in the areas of genetic testing and results, as well as regarding beliefs about personal benefit. Gaps in understanding of genetic testing may have implications for concerns. Concerns may be milder if individuals do not fully understand the potential for confidentiality to be compromised, genetic information to be shared, and samples to remain even if they withdraw. Such misunderstanding may be caused by the terminology or language used. For example, in the biomedical community, the definition of clinical utility may be relatively narrow com- 
pared to the public's perception. Additionally, varying perceptions of the treatability of $\mathrm{AD}$ may compound this confusion [24]. While mild concerns are encouraging for research engagement, information should be conveyed in an easily understandable way to ensure participants make informed decisions. For example, our participants seemed to interpret the goal of research as to help them directly, many believing they would receive information about their own risk for $\mathrm{AD}$ and be contacted if their genes showed any disease risk factors. While participation in a research study may provide some personal benefit and, on occasion, provide personal disease risk information, in many instances this is not the case. Special care should be taken with the terminology and language selected to help ensure clear expectations. Researchers may want to clarify with potential participants their goals when joining a study, in order to ensure that their goals are aligned with their research involvement and to evaluate risks and benefits [25].

While prior research suggested many individuals can distinguish hopes for benefit from expectations of benefit, not all research participants are able to do so [26]. Misperceptions of personal benefit may have implications for participant retention; individuals who engage with false perceptions of feedback may be more likely to withdraw when they fail to get the anticipated feedback. With the complexity involved in genetic research and the prospect of incidental findings, informed consent should be explicit about research results (primary and incidental) and whether and when participants may receive personal information [27].

Disclosure of genetic results is an issue that is hotly debated by research communities and ethicists [28]. Consistent with our findings that participants desire disease risk information, previous research has also suggested that a majority of participants favor knowing their genetic test results and are psychologically able to deal with such information, and that such knowledge may even serve as an incentive for research participation [29-31]. While there are logistical and ethical challenges that can result from sharing genetic results [32], the research community should work towards finding a balance between the complexity involved with sharing individualized results and the benefits of disclosure for maintaining trust and giving a sense of involvement and reciprocity. While some efficiency may be lost and costs accrued by incorporating a disclosure process [33], recruitment challenges may be somewhat ameliorated over time as research becomes more participant centered.
While no significant relationship between comprehension and concerns was found, concerns were related to education, respondent group, and race. Surprisingly, those with higher levels of education had higher levels of concern. Perhaps individuals with more education are more aware of the potential - both good and bad - of genetic information and therefore have more concerns. Those with lower levels of education had more comprehension difficulties but fewer concerns regarding genetic information. This raises the unwelcome possibility that individuals with lower levels of education may have knowledge gaps that pose challenges to fully comprehending potential risks [34].

Similarly, the finding that minorities had a higher level of concern than White participants is in line with numerous studies that indicate higher levels of mistrust of health research and researchers among minority populations [35, 36]. This mistrust may stem from various sources, including a history of research mistreatment and misuse of genetic information, e.g., the prominent case of Henrietta Lacks. The current findings may provide some insight into approaches for addressing lower rates of minority participation in genetic research [37], including educational efforts accompanied by efforts to build relationships and address mistrust and research concerns [38]. While not all concerns can be fully addressed, efforts to communicate research safeguards may need to be strengthened. Some of these efforts may be more successful if information comes from sources potential participants already are familiar with and trust and respect, such as healthcare providers [39]. Greater transparency about the use and sharing of genetic information may also help alleviate some concerns. With the alleviation of some concerns, hopefully barriers will be reduced and participation among minorities might increase. It is important to note that some concerns stem directly from the research, whereas others may be related to broader issues regarding trust in researchers and institutions [40]. Addressing these factors may require broader efforts including the development of innovative partnerships between research entities and community organizations [41].

Another unanticipated finding in our study was that participants were generally unconcerned about drug companies obtaining their data, or about researchers making a profit from their genetic information without sharing these profits. Of note, however, over $20 \%$ of the respondents replied "not sure" to these items, suggesting the possibility that upon further reflection concerns may be somewhat greater, or that this may be a more nuanced issue than previously recognized. Perhaps those who see 
the benefits of these instances of sharing are those who are generally more trusting of the research process and may be less concerned about how their information is shared. This question will require further attention in the future to ensure respect for participants' autonomy.

Willingness to participate generally was very high across all groups, consistent with previous research showing generally positive attitudes towards genetic research [42]. This finding was also somewhat expected given that the participants surveyed were either already involved in $\mathrm{AD}$ research or had previously expressed a willingness to be contacted for aging-related research. However, given that many of the VRL participants were research naïve and likely had not previously considered AD genetic testing, the high willingness observed is still noteworthy. Given respondents' receptivity to the idea of $\mathrm{AD}$ genetic research, greater promotion of opportunities in general may increase participation. Prior research has suggested one of the major barriers to participation is simply never being asked [39]. Additionally, the finding that knowledge and willingness were not significantly related, but that willingness was inversely related to concerns, suggests that research willingness may be influenced more by comfort with research engagement than by knowledge per se [31]. Directly addressing concerns and highlighting the benefits and value of participation, rather than broader research education efforts, may be key to increasing public participation. Future research will need to explore whether the same strategies are appropriate for those who have not previously demonstrated any research interest.

\section{Limitations}

This study's main limitation is generalizability. While the UKADC response rate was $56.7 \%$, the VRL response rate was $34.5 \%$. Although somewhat anticipated by the lack of an active relationship with the VRL group, this response rate raises questions about the generalizability of the VRL responses to the Kentucky older adult population. The possibility for nonresponse bias, where respondents may be more knowledgeable and positive about $\mathrm{AD}$ genetic research than nonrespondents, exists. The sample's limited diversity and high educational attainment also limit generalizability. While relatively low, the number of minority participants was in line with Kentucky demographics [43]. The VRL members had previously expressed a willingness to be contacted about research; accordingly, research willingness is likely higher than in the general public. Differences between respondents and nonrespondents also suggest that respondents could po-

Understanding Genetic Research on AD tentially be more comfortable with the concept of AD genetic research than nonrespondents. Accordingly, while this study likely overestimates the $\mathrm{AD}$-related genetic research willingness of older adults from the general public, the findings regarding comprehension gaps and the role of concerns remain essential for consideration when designing future outreach and recruitment efforts, where these gaps and concerns will likely be even greater.

Another limitation lies in the hypothetical nature of the research. Real-world concerns and engagement decisions may differ from hypothetical assessments. Research engagement may also be related to factors beyond the individual that were not assessed, such as lack of access to institutions conducting $\mathrm{AD}$ genetic research, lack of/limited racial and cultural diversity among research investigators and staff, and time and travel challenges involved in research participation. Future research should move from hypothetical willingness to actual research engagement.

In this study, the participants completed the survey in isolation, with no one immediately available for questions or clarification. Research consent processes are interactive and allow for opportunities for dialogue and clarification. Our intention was not to mirror a consent process, but rather to gain insight into participants' understanding and views of $\mathrm{AD}$ genetic research. Most of the public never gets to the point of discussing a research consent form, and even for those who do, initial review often occurs prior to coming in for the actual consent process; accordingly, investigating the public understanding and attitudes without the benefit of active researcher interaction is important.

\section{Conclusions}

Despite the noted limitations, this study shows that older adults recognize the importance of genetic research. Extra efforts to bring awareness of research participation opportunities to the public and to assuage fears about the use of genetic information should be made to capitalize on this interest. As new genetic discoveries continue to emerge, we should remain cognizant of the public's attitudes and beliefs and ensure that outreach materials and research design choices reflect community wishes and expectations, especially as efforts to increase participation among vulnerable and underrepresented populations continue. In the future, we will also explore knowledge, concerns, and research willingness across older adults who have not previously expressed any research interest. 


\section{Acknowledgements}

Thanks to all of our survey respondents who took the time to complete and return our survey. Thanks also to the following students who assisted with data entry: Hannah Schuler, Megan Higgins, Ying Liu, and Holden Huffman.

\section{Statement of Ethics}

Approval for this research was received from the University of Kentucky IRB. No formal documentation of consent was required.

\section{Disclosure Statement}

None of the authors have any conflicts of interest to disclose.

\section{Funding Sources}

The project described was supported by the National Center for Research Resources and the National Center for Advancing Translational Sciences, National Institutes of Health (through grant UL1TR001998), and the National Institute on Aging (P30 AG028383). The content is solely the responsibility of the authors and does not necessarily represent the official views of the National Institutes of Health.

\section{References}

1 Van Cauwenberghe C, Van Broeckhoven C, Sleegers K. The genetic landscape of Alzheimer disease: clinical implications and perspectives. Genet Med. 2016 May;18(5):421-30.

2 Karch CM, Cruchaga C, Goate AM. Alzheimer's disease genetics: from the bench to the clinic. Neuron. 2014 Jul;83(1):11-26.

3 Chase GA, Geller G, Havstad SL, Holtzman NA, Bassett SS. Physicians' propensity to offer genetic testing for Alzheimer's disease: results from a survey. Genet Med. 2002 Jul-Aug;4(4): 297-303.

4 Goldman JS, Hahn SE, Catania JW, LaRusseEckert S, Butson MB, Rumbaugh M, et al.; American College of Medical Genetics and the National Society of Genetic Counselors. Genetic counseling and testing for Alzheimer disease: joint practice guidelines of the American College of Medical Genetics and the $\mathrm{Na}$ tional Society of Genetic Counselors. Genet Med. 2011 Jun;13(6):597-605.

5 Foster TC. Biological markers of age-related memory deficits: treatment of senescent physiology. CNS Drugs. 2006;20(2):153-66.

6 Green RC, Lautenbach D, McGuire AL. GINA, genetic discrimination, and genomic medicine. N Engl J Med. 2015 Jan;372(5): 397-9.

7 Collins FS, Green ED, Guttmacher AE, Guyer MS; US National Human Genome Research Institute. A vision for the future of genomics research. Nature. 2003 Apr;422(6934):83547.

8 Neumann PJ, Hammitt JK, Mueller C, Fillit HM, Hill J, Tetteh NA, et al. Public attitudes about genetic testing for Alzheimer's disease. Health Aff (Millwood). 2001 Sep-Oct;20(5): 252-64.

9 Hipps YG, Roberts JS, Farrer LA, Green RC. Differences between African Americans and Whites in their attitudes toward genetic testing for Alzheimer's disease. Genet Test. 2003; 7(1):39-44.

10 Fernandez CV, Kodish E, Weijer C. Informing study participants of research results: an ethical imperative. IRB. 2003 May-Jun;25(3): 12-9.
11 Wolf SM, Lawrenz FP, Nelson CA, Kahn JP, Cho MK, Clayton EW, et al. Managing incidental findings in human subjects research: analysis and recommendations. J Law Med Ethics. 2008 Summer;36(2):219-48, 211.

12 Ostergren JE, Gornick MC, Carere DA, Kalia SS, Uhlmann WR, Ruffin MT, et al.; PGen Study Group. How Well Do Customers of Direct-to-Consumer Personal Genomic Testing Services Comprehend Genetic Test Results? Findings from the Impact of Personal Genomics Study. Public Health Genomics. 2015; 18(4):216-24

13 Kerath SM, Klein G, Kern M, Shapira I, Witthuhn J, Norohna N, et al. Beliefs and attitudes towards participating in genetic research - a population based cross-sectional study. BMC Public Health. 2013 Feb;13(1):114.

14 Mezuk B, Eaton WW, Zandi P. Participant characteristics that influence consent for genetic research in a population-based survey: the Baltimore Epidemiologic Catchment Area follow-up. Community Genet. 2008; 11(3):171-8.

15 Kaufman DJ, Baker R, Milner LC, Devaney S, Hudson KL. A Survey of U.S Adults' Opinions about Conduct of a Nationwide Precision Medicine Initiative ${ }^{\circledR}$ Cohort Study of Genes and Environment. PLoS One. 2016 Aug;11(8):e0160461.

16 Akinleye I, Roberts JS, Royal CD, Linnenbringer E, Obisesan TO, Fasaye GA, et al. Differences between African American and White research volunteers in their attitudes, beliefs and knowledge regarding genetic testing for Alzheimer's disease. J Genet Couns. 2011 Dec;20(6):650-9.

17 Schmitt FA, Nelson PT, Abner E, Scheff S, Jicha GA, Smith C, et al. University of Kentucky Sanders-Brown healthy brain aging volunteers: donor characteristics, procedures and neuropathology. Curr Alzheimer Res. 2012 Jul;9(6):724-33.

18 Morris JC. The Clinical Dementia Rating $(\mathrm{CDR})$ : current version and scoring rules. Neurology. 1993 Nov;43(11):2412-4.
19 Joffe S, Cook EF, Cleary PD, Clark JW, Weeks JC. Quality of informed consent: a new measure of understanding among research subjects. J Natl Cancer Inst. 2001 Jan;93(2):13947.

20 Buccini LD, Iverson D, Caputi P, Jones C, Gho S. Assessing Clinical Trial Informed Consent Comprehension in Non-Cognitively-Impaired Adults: A Systematic Review of Instruments. Res Ethics Rev. 2009;5(1):3-8.

21 Jefford M, Mileshkin L, Matthews J, Raunow H, O'Kane C, Cavicchiolo T, et al. Satisfaction with the decision to participate in cancer clinical trials is high, but understanding is a problem. Support Care Cancer. 2011 Mar;19(3): 371-9.

22 Christianson CA, Powell KP, Hahn SE, Bartz D, Roxbury T, Blanton SH, et al.; Genomedical Connection. Findings from a community education needs assessment to facilitate the integration of genomic medicine into primary care. Genet Med. 2010 Sep;12(9):587-93.

23 Shoemaker SJ, Brach C, Edwards A, Chitavi SO, Thomas R, Wasserman M. Opportunities to Improve Informed Consent with AHRQ Training Modules. Jt Comm J Qual Patient Saf. 2018 Jun;44(6):343-52.

24 Murphy J, Scott J, Kaufman D, Geller G, LeRoy L, Hudson K. Public expectations for return of results from large-cohort genetic research. Am J Bioeth. 2008 Nov;8(11):36-43.

25 Grosse SD, McBride CM, Evans JP, Khoury MJ. Personal utility and genomic information: look before you leap. Genet Med. 2009 Aug;11(8):575-6.

26 Peay HL, Tibben A, Fisher T, Brenna E, Biesecker BB. Expectations and experiences of investigators and parents involved in a clinical trial for Duchenne/Becker muscular dystrophy. Clin Trials. 2014 Feb;11(1):77-85.

27 Appelbaum PS, Waldman CR, Fyer A, Klitzman R, Parens E, Martinez J, et al. Informed consent for return of incidental findings in genomic research. Genet Med. 2014 May;16(5):367-73. 
28 Wallace SE, Kent A. Population biobanks and returning individual research results: mission impossible or new directions? Hum Genet. 2011 Sep;130(3):393-401.

29 Kaufman D, Murphy J, Scott J, Hudson K. Subjects matter: a survey of public opinions about a large genetic cohort study. Genet Med. 2008 Nov; 10(11):831-9.

30 Meulenkamp TM, Gevers SK, Bovenberg JA, Koppelman GH, van Hylckama Vlieg A, Smets EM. Communication of biobanks' research results: what do (potential) participants want? Am J Med Genet A. 2010 Oct; 152A(10):2482-92.

31 Grill JD, Zhou Y, Elashoff D, Karlawish J. Disclosure of amyloid status is not a barrier to recruitment in preclinical Alzheimer's disease clinical trials. Neurobiol Aging. 2016 Mar;39: $147-53$.

32 Bollinger JM, Scott J, Dvoskin R, Kaufman D. Public preferences regarding the return of individual genetic research results: findings from a qualitative focus group study. Genet Med. 2012 Apr;14(4):451-7.
33 Jarvik GP, Amendola LM, Berg JS, Brothers K, Clayton EW, Chung W, et al.; eMERGE ActROR Committee and CERC Committee; CSER Act-ROR Working Group. Return of genomic results to research participants: the floor, the ceiling, and the choices in between. Am J Hum Genet. 2014 Jun;94(6):818-26.

34 Coakley M, Fadiran EO, Parrish LJ, Griffith RA, Weiss E, Carter C. Dialogues on diversifying clinical trials: successful strategies for engaging women and minorities in clinical trials. J Womens Health (Larchmt). 2012 Jul; 21(7):713-6.

35 Corbie-Smith G, Thomas SB, Williams MV, Moody-Ayers S. Attitudes and beliefs of African Americans toward participation in medical research. J Gen Intern Med. 1999 Sep; 14(9):537-46.

36 Green BL, Partridge EE, Fouad MN, Kohler C, Crayton EF, Alexander L. African-American attitudes regarding cancer clinical trials and research studies: results from focus group methodology. Ethn Dis. 2000;10(1):76-86.

37 McQuillan GM, Porter KS, Agelli M, Kington R. Consent for genetic research in a general population: the NHANES experience. Genet Med. 2003 Jan-Feb;5(1):35-42.

38 Yancey AK, Ortega AN, Kumanyika SK. Effective recruitment and retention of minority research participants. Annu Rev Public Health. 2006;27(1):1-28.
39 Millon Underwood S, Buseh AG, Kelber ST, Stevens PE, Townsend L. Enhancing the participation of African Americans in health-related genetic research: findings of a collaborative academic and community-based research study. Nurs Res Pract. 2013;2013:749563.

40 Williams MM, Scharff DP, Mathews KJ, Hoffsuemmer JS, Jackson P, Morris JC, et al. Barriers and facilitators of African American participation in Alzheimer disease biomarker research. Alzheimer Dis Assoc Disord. 2010 Jul-Sep;24 Suppl:S24-9.

41 Watson JL, Ryan L, Silverberg N, Cahan V, Bernard MA. Obstacles and opportunities in Alzheimer's clinical trial recruitment. Health Aff (Millwood). 2014 Apr;33(4):574-9.

42 Henderson G, Garrett J, Bussey-Jones J, Moloney ME, Blumenthal C, Corbie-Smith G. Great expectations: views of genetic research participants regarding current and future genetic studies. Genet Med. 2008 Mar;10(3): 193-200.

43 United States Census Bureau. Quick Facts Kentucky. Population Estimates, July 1, 2016 [Internet]. United States Census Bureau; 2016. Available from: https://www.census. gov/quickfacts/fact/table/KY\#viewtop. 